\title{
Eye Care Quality and Accessibility Improvement in the Community (EQUALITY): impact of an eye health education program on patient knowledge about glaucoma and attitudes about eye care
}

\author{
This article was published in the following Dove Press journal: \\ Patient Related Outcome Measures \\ 19 May 2016 \\ Number of times this article has been viewed
}

\author{
Lindsay A Rhodes' \\ Carrie E Huisingh' \\ Gerald McGwin Jr',2 \\ Stephen T Mennemeyer ${ }^{3}$ \\ Mary Bregantini ${ }^{4}$ \\ Nita Patel ${ }^{4}$ \\ Jinan Saaddine ${ }^{5}$ \\ John E Crews ${ }^{5}$ \\ Christopher A Girkin' \\ Cynthia Owsley' \\ 'Department of Ophthalmology, \\ School of Medicine, ${ }^{2}$ Department \\ of Epidemiology, ${ }^{3}$ Department of \\ Health Care Organization and Policy, \\ School of Public Health, University of \\ Alabama at Birmingham, Birmingham, \\ $\mathrm{AL},{ }^{4}$ Prevent Blindness, Chicago, IL, \\ USA; ${ }^{5}$ Vision Health Initiative, Division \\ of Diabetes Translation, Centers for \\ Disease Control and Prevention, \\ Atlanta, GA, USA
}

\begin{abstract}
Purpose: To assess the impact of the education program of the Eye Care Quality and Accessibility Improvement in the Community (EQUALITY) telemedicine program on at-risk patients' knowledge about glaucoma and attitudes about eye care as well as to assess patient satisfaction with EQUALITY.
\end{abstract}

Patients and methods: New or existing patients presenting for a comprehensive eye exam (CEE) at one of two retail-based primary eye clinics were enrolled based on $\geq 1$ of the following at-risk criteria for glaucoma: African Americans $\geq 40$ years of age, Whites $\geq 50$ years of age, diabetes, family history of glaucoma, and/or preexisting diagnosis of glaucoma. A total of 651 patients were enrolled. A questionnaire was administered prior to the patients' CEE and prior to the patients receiving any of the evidence-based eye health education program; a follow-up questionnaire was administered 2-4 weeks later by phone. Baseline and followup patient responses regarding knowledge about glaucoma and attitudes about eye care were compared using McNemar's test. Logistic regression models were used to assess the association of patient-level characteristics with improvement in knowledge and attitudes. Overall patient satisfaction was summarized.

Results: At follow-up, all patient responses in the knowledge and attitude domains significantly improved from baseline ( $P \leq 0.01$ for all questions). Those who were unemployed (odds ratio $=0.63,95 \%$ confidence interval $=0.42-0.95, P=0.026$ ) or had lower education (odds ratio $=0.55,95 \%$ confidence interval $=0.29-1.02, P=0.058$ ) were less likely to improve their knowledge after adjusting for age, sex, race, and prior glaucoma diagnosis. This association was attenuated after further adjustment for other patient-level characteristics. Ninety-eight percent $(n=501)$ of patients reported being likely to have a CEE within the next 2 years, whereas $63 \%(n=326)$ had a CEE in the previous 2 years. Patient satisfaction with EQUALITY was high (99\%).

Conclusion: Improved knowledge about glaucoma and a high intent to pursue eye care may lead to improved detection of early disease, thus lowering the risk of blindness.

Keywords: patient satisfaction, telemedicine, blindness prevention, patient-related outcome

\section{Introduction}

Glaucoma, specifically primary open-angle glaucoma (POAG), is a chronic, progressive optic neuropathy characterized by thinning of the retinal nerve fiber layer and gradual loss of vision starting in the peripheral visual field and extending to central vision in advanced disease. The at-risk population for POAG in the USA is expansive, with older age being the primary risk factor, followed by African Americans $\geq 40$ years old, Whites 
of non-Hispanic origin $\geq 50$ years old, those with a family history, and older persons with diabetes. ${ }^{1-10}$ The prevalence of POAG reflects these risk factors as it increases with age, affecting more than $1.8 \%$ of the US population above 40 years of age, but increasing to $23.2 \%$ among African Americans and $9.4 \%$ among Whites over the age of 75 years. ${ }^{11}$ In addition, it is estimated that nearly half of those with glaucoma may not know they have the disease, because symptoms appear late in the disease course. ${ }^{12}$ POAG is 4-5 times higher in African Americans compared to Whites. ${ }^{2,13}$ In African Americans, POAG appears at a younger age, progresses more rapidly, and is frequently more advanced at the time of diagnosis than in White patients. ${ }^{14-20}$

Glaucoma is a potentially blinding disease that, if detected in early stages, can be controlled, resulting in preservation of vision. Persons at increased risk for glaucoma are often from populations with low rates of eye care utilization, ${ }^{13,21-25}$ stemming in part from reduced accessibility to eye care, cost, and inadequate knowledge about the importance of routine eye care and common eye diseases. ${ }^{25-29}$ Interventions that improve early detection of glaucoma, including those that make care more accessible and convenient, and that increase patient knowledge, through the use of evidence-based eye health education, could improve the health and well-being of persons at risk for glaucoma. Telemedicine, specifically incorporated in glaucoma detection and management, is such an intervention and has the potential to reach segments of the population at risk for glaucoma who also have reduced accessibility to eye care. ${ }^{30-40}$ Eye health education can be built into interactions between the clinician/clinic staff and the patient, with the goals of increasing patient knowledge about eye disease, facilitating adherence to attending recommended and routine eye appointments, and improving adherence to treatment recommendations. ${ }^{27,41-44}$

The Eye Care Quality and Accessibility Improvement in the Community (EQUALITY) demonstration program evaluated the feasibility of a telemedicine glaucoma detection and management program deployed in retail-based primary eye care practices (Walmart Vision Centers) serving communities with high percentages of persons at risk for glaucoma, including African Americans. ${ }^{45}$ The EQUALITY program used an evidence-based eye health education program specifically designed to educate patients about glaucoma directly through a variety of materials and to educate eye clinic staff about glaucoma, so that they could skillfully impart information to patients. ${ }^{27,28,42}$

The purpose of this study was to assess the impact of the eye health education program of the EQUALITY telemedicine program on at-risk patients' knowledge about glaucoma and attitudes about eye care. A secondary aim was to describe the patient satisfaction with the eye care experience in the EQUALITY program.

\section{Materials and methods}

The Institutional Review Board of the University of Alabama at Birmingham (UAB) approved the study and issued a waiver of informed consent since study procedures were usual care. The geographical setting for the study consisted of retailbased primary eye clinics (Walmart Vision Centers adjacent to Walmart Supercenters) in two regions of Alabama with high percentages of African Americans. One clinic was in Homewood, Alabama, a community within the metropolitan area of Birmingham, Alabama, the largest city in the state. Birmingham's population is approximately $73 \%$ African American. The second clinic was in Tuscaloosa, Alabama, in Tuscaloosa County. Tuscaloosa County is located in west Alabama at the edge of Alabama's Black Belt region, named for its rich black soil. The Black Belt is a rural area with one of the highest poverty rates in the USA and has been characterized as "Alabama's Third World". ${ }^{46}$ It has among the highest concentrations of African American residents of any rural region of the country, representing more than $50 \%$ of the population.

Participants in the study were new or existing patients presenting for a comprehensive eye exam (CEE) at the retail-based clinics who met any of the following criteria: 1) African Americans $\geq 40$ years old, 2) Whites $\geq 50$ years old, 3) persons of any age or race/ethnicity with diabetes, 4) persons of any age or race/ethnicity with a glaucoma-associated diagnosis (GAD) (glaucoma suspect, ocular hypertension, and POAG), and 5) persons with a self-reported family history of POAG. These criteria were selected because they are established risk factors for glaucoma. ${ }^{47}$ The enrollment period was from May 2013 to May 2014 for the Tuscaloosa Vision Center, and May 2013 to July 2014 for the Homewood Vision Center.

All eligible patients who enrolled in the study received a CEE by the optometrist at the clinic. The CEE consisted of a collection of demographic and other information (birthdate, sex, race/ethnicity, address of residence, and health insurance status), patient history (chief complaint, history of presenting illness, ocular history, medical history, and family and social history), blood pressure, ocular examination (visual acuity with walk-in and best correction, refraction, color vision, applanation tonometry, pachymetry, undilated slit-lamp anterior segment examination, undilated gonioscopy, and 
dilated fundus examination), and ocular imaging (spectral domain ocular coherence tomography, stereoscopic optic nerve photography, and automated visual field testing with Swedish interactive thresholding algorithm [SITA] 24-2). During the clinic visit, evidence-based eye health education was delivered to the patients (see "Eye health education" section). After the CEE, the optometrist determined the patients' ocular diagnosis and whether the patient had normal ocular results, a GAD, or other ocular disease. All CEE and imaging data were transferred to a remote Glaucoma Reading Center at the UAB Department of Ophthalmology, where a fellowship-trained glaucoma subspecialist reviewed the data within 1 week and communicated with the optometrist any changes in the diagnosis and treatment plan. A complete description of the EQUALITY telemedicine protocol has been published previously. ${ }^{45}$

\section{Questionnaire administration}

The project coordinator verbally administered a questionnaire while the patient was dilating for the CEE and before the patient received any results or diagnostic impressions from the optometrist. This questionnaire contained the following item domains (Table 1), which were adapted from various questionnaires used frequently in the literature: 1) eye care utilization, ${ }^{48}$ 2) trouble seeing, 3) visual task difficulty, ${ }^{49}$ 4) accessibility/transportation, ${ }^{27} 5$ ) review of chronic medical conditions, ${ }^{50} 6$ ) attitudes about eye care, ${ }^{27} 7$ ) knowledge about glaucoma,${ }^{51} 8$ ) difficulty paying for eye care, ${ }^{27}$ and 9) education completed.

\section{Eye health education}

The eye health education program administered in this project was specifically designed for the program's purposes by the authors. The first education goal was directed at educating the clinic staff about how to impart evidence-based information to their patients about GAD, because all patients in the program were at risk for glaucoma. Staff education occurred before the start of the project. This training was accomplished through the Glaucoma Educator Training Course, ${ }^{52}$ a free 1-hour web-based training program, written at the ninthgrade literacy level. The program was based on materials available through Prevent Blindness ${ }^{53}$ and UAB's previous

Table I Baseline questionnaire

\begin{tabular}{|c|c|}
\hline Domain & Item synopsis \\
\hline Eye care utilization & When was the last time you had an eye exam in which your pupils were dilated? \\
\hline Trouble seeing & $\begin{array}{l}\text { Do you have any trouble seeing, even when wearing glasses or contact lenses? } \\
\text { (Yes/no) }\end{array}$ \\
\hline \multirow[t]{5}{*}{ Visual task difficulty } & Because of your eyesight: \\
\hline & How much difficulty do you have reading ordinary print in newspapers? \\
\hline & How much difficulty do you have going down steps, stairs, or curbs in dim light or at night? \\
\hline & How much difficulty do you have finding something on a crowded shelf? \\
\hline & $(\text { Difficulty scale) })^{\mathrm{a}}$ \\
\hline \multirow[t]{3}{*}{ Accessibility/transportation } & How much difficulty did you have finding a way to get here? (Difficulty scale) ${ }^{a}$ \\
\hline & I'm more likely to go to the eye doctor if the doctor's office is near a place I shop. \\
\hline & $(\text { Agree/disagree scale })^{b}$ \\
\hline \multirow[t]{2}{*}{ Review of chronic medical conditions } & Have you ever been told by a doctor or other health professional that you have[...]? \\
\hline & $($ Yes/no) \\
\hline \multirow[t]{3}{*}{ Attitudes about eye care } & It is important to go to the eye doctor at least once every 2 years. \\
\hline & There is no need to go to the eye doctor if you're not having a problem with your eyes. \\
\hline & $(\text { Agree/disagree scale })^{\mathrm{b}}$ \\
\hline \multirow[t]{6}{*}{ Knowledge about glaucoma } & A person can have glaucoma and not know it. \\
\hline & Glaucoma can be controlled. \\
\hline & Vision lost from glaucoma can be restored. \\
\hline & A complete glaucoma exam consists only of measuring eye pressure. \\
\hline & People at risk for glaucoma should have an eye examination through dilated pupils. \\
\hline & (True/false) \\
\hline \multirow[t]{5}{*}{ Cost of eye care } & Is the cost of an eye exam a problem for you? \\
\hline & Is the cost of buying eyeglasses a problem for you? \\
\hline & If the doctor prescribed eye drops for you in order to treat an eye problem you have, would the cost \\
\hline & of prescription eye drops be a problem for you? \\
\hline & $\left(\right.$ Problem Scale) ${ }^{c}$ \\
\hline
\end{tabular}

Notes: a Difficulty scale response options: no difficulty, a little difficulty, moderate difficulty, extreme difficulty, unable to do because of eyesight, unable to do this for other

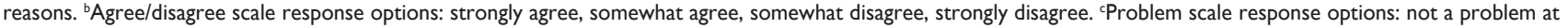
all, a little bit of a problem, somewhat of a problem, a big problem. 
eye health education program, InCHARGE (in communities helping African Americans receive general eye care). ${ }^{25,27,42,54}$ The EQUALITY education program provided training on what glaucoma is and how it is treated, persons at risk for glaucoma, how to discuss glaucoma with patients, and how to help patients overcome the barriers to care. The web-based course was followed by an online test to ensure that messages were successfully retained by the trainee. All clinic staff members were required to pass the online test with unlimited attempts, upon which they received a certificate of completion from Prevent Blindness.

The second education goal was to directly educate patients at risk for glaucoma using several approaches. The baseline questionnaire described earlier was administered before presentation of eye health education in order to ascertain changes in knowledge from before to after the educational information and clinic visit. Three educational formats, written at a fifth-grade literacy level, were used to directly educate patients: videos, package inserts, and posters.

1. Videos for patients: Two short videos presented messages about the importance of routine dilated CEE for persons who are at risk for glaucoma. These videos were approximately 3 minutes long each and were shown to the patient by the project coordinator on an iPad (Apple Inc., Cupertino, CA, USA) while they were waiting for their pupils to dilate. The videos are available at the Glaucoma Educator Course website. ${ }^{52}$

2. Package "inserts" on glaucoma: These were colorful and to-the-point brochures on who is at risk for glaucoma and the importance of routine CEE for this at-risk population. The inserts were provided to patients after the videos were presented and were also placed in the bags of purchases made by customers in the Walmart Optical Shop and the Walmart Pharmacy in an effort to educate the general public.

3. Posters: One poster $(18 \times 24$ inches $)$ containing material identical to the inserts was positioned in the Vision Center, the Walmart Optical Shop, and Walmart Pharmacy, with three posters at each study site.

\section{Telephone follow-up questionnaire}

Approximately 2-4 weeks after a patient participated in EQUALITY, we recontacted the participant by telephone

Table 2 Follow-up questionnaire

\begin{tabular}{|c|c|}
\hline Domain & Item synopsis \\
\hline Patient satisfaction & $\begin{array}{l}\text { How satisfied were you with your comprehensive eye exam visit? } \\
\text { (Satisfied/dissatisfied scale) }^{\mathrm{a}} \\
\text { How convenient was it for you to have your eye exam at this location? } \\
\text { (Convenient/inconvenient scale) }^{\mathrm{b}} \\
\text { Would you recommend this eye clinic to a friend or family member? } \\
\text { (Likely scale) }^{c}\end{array}$ \\
\hline Other uses of large retailer & $\begin{array}{l}\text { While you were there for your exam, did you use the Walmart pharmacy? } \\
\text { Other than the pharmacy, did you do any shopping at Walmart on that day? } \\
\text { (Yes/no) }\end{array}$ \\
\hline Accessibility/transportation & $\begin{array}{l}\text { I'm more likely to go to the eye doctor if the doctor's office is near a place I shop. } \\
\text { (Agree/disagree scale) })^{d}\end{array}$ \\
\hline Eye care utilization & $\begin{array}{l}\text { How likely are you to go for a comprehensive eye exam in the next year or } 2 \text { ? } \\
\text { (Likely scale) }^{c}\end{array}$ \\
\hline Attitudes about eye care & $\begin{array}{l}\text { It is important to go to the eye doctor at least once every } 2 \text { years. } \\
\text { There is no need to go to the eye doctor if you're not having a problem with your eyes. } \\
\text { (Agree/disagree scale) }^{\text {d }}\end{array}$ \\
\hline Knowledge about glaucoma & $\begin{array}{l}\text { A person can have glaucoma and not know it. } \\
\text { Glaucoma can be controlled. } \\
\text { Vision lost from glaucoma can be restored. } \\
\text { A complete glaucoma exam consists only of measuring eye pressure. } \\
\text { People at risk for glaucoma should have an eye examination through dilated pupils. } \\
\text { (True/false) }\end{array}$ \\
\hline Cost of eye care & $\begin{array}{l}\text { Is the cost of an eye exam a problem for you? } \\
\text { Is the cost of buying eyeglasses a problem for you? } \\
\text { If the doctor prescribed eye drops for you in order to treat an eye problem you have, would the cost } \\
\text { of prescription eye drops be a problem for you? } \\
\text { (Problem scale) }\end{array}$ \\
\hline
\end{tabular}

Notes: aSatisfied/dissatisfied scale response options: very satisfied, satisfied, dissatisfied, very dissatisfied. ${ }^{b}$ Convenient/inconvenient scale response options: very convenient, convenient, inconvenient, very inconvenient. 'Likely scale response options: very likely, somewhat likely, not very likely, not at all likely. ${ }^{\mathrm{d} A g r e e / d i s a g r e e ~ s c a l e ~ r e s p o n s e ~}$ options: strongly agree, somewhat agree, somewhat disagree, strongly disagree. eProblem scale response options: not a problem at all, a little bit of a problem, somewhat of a problem, a big problem. 
to repeat the administration of some questionnaire items as well as to add some new items (Table 2). This telephone questionnaire allowed for the evaluation of the impact of the EQUALITY program with respect to the following domains: 1) patient satisfaction, 2) other uses of the large retailer adjacent to the clinic on the day the patient had an appointment, 3) accessibility/transportation, ${ }^{27} 4$ ) eye care utilization and whether prescriptions from the optometrists were filled, ${ }^{48} 5$ ) attitudes about eye care, ${ }^{27} 6$ ) knowledge about glaucoma, ${ }^{51}$ and 7) difficulty paying for eye care. ${ }^{27}$ Telephone calls were conducted by trained program staff in the UAB Department of Ophthalmology. Up to ten attempts to contact each patient were made, ensuring that these calls were made at different times of the day in order to facilitate reaching the patient. All questionnaire responses were recorded in the project database, but the responses were not made available to the optometrists or ophthalmologists managing the care of these patients.

\section{Variable definitions}

Five true/false questions were used to assess glaucoma knowledge (Tables 1 and 2). The number of correct answers was summed and ranged from 0 to 5 . An improvement in glaucoma knowledge was defined as answering one or more additional knowledge questions correctly at follow-up compared to baseline. Attitude about eye care was assessed using two questions that asked participants to indicate the importance of going to an eye doctor on a 4-point agree/ disagree scale (Tables 1 and 2). The number of questions that the participant responded positively with "Strongly agree" or "Somewhat agree" was summed and ranged from 0 to 2 , with a positive attitude defined as answering both questions positively. An improvement in attitude about eye care was defined as positively answering one or more additional attitude questions at follow-up compared to baseline. The intent to pursue eye care was defined as a response of "Very likely" or "Somewhat likely" on the Likely scale (Table 2). Patient characteristic variables are defined as follows: prior glaucoma diagnosis was defined as whether the patient reported receiving a GAD at any previous time; distance traveled was defined as the distance in miles from the patient's home address to the clinic address one way, using Google Maps Driving Directions program (Google, Inc., Mountain View, CA, USA); visual acuity was defined as the distance visual acuity of the better eye measured as either best-corrected visual acuity or walk-in visual acuity with habitual correction, which was expressed as the logarithm of the minimum angle of resolution (logMAR), with visual acuity impairment defined as $0.3 \log$ MAR (20/40) or worse ${ }^{55}$ and the visual field was defined using the mean deviation in decibels of the better eye if the patient had a visual field performed.

\section{Statistical analysis}

The present analysis reports data from participants who completed the questionnaire domains of knowledge about glaucoma, attitudes about eye care, and eye care utilization on both the baseline and follow-up questionnaires, as well as the satisfaction domain of the follow-up questionnaire. Of the 651 patients enrolled in the EQUALITY program at the two sites, $518(80 \%)$ met these criteria and were included in this analysis. Compared to those who were excluded, participants in this analysis were older ( 55.1 vs 51.8 years, $P<0.01)$ but were similar in terms of race and sex $(P>0.70$ for both).

Demographic, health, and ocular characteristics and distance traveled were described for the overall sample. McNemar's test was used to assess differences in knowledge about glaucoma and attitudes about eye care between the baseline and follow-up patient responses. A statistically significant test indicated the proportions were different between the baseline and follow-up visits. Multivariate logistic regression models were used to assess the independent association of patient characteristics (age, sex, race, prior glaucoma diagnosis, employment status, education level, comorbidities, visual acuity, and visual field mean deviation) with improvement in knowledge about glaucoma and attitudes about eye care. Patients who correctly answered all five knowledge questions and positively answered both attitude questions at baseline and follow-up were analyzed separately. Overall patient satisfaction was summarized for the study sample. $P$-values less than 0.05 were considered statistically significant.

\section{Results}

Study participants ranged in age from 20 to 90 years old (mean: 55.1 years, standard deviation [SD]: 12.9) (Table 3). The majority were female (65\%), African American (64\%), and established patients in the clinic (67\%). The average distance from the patients' home to the eye clinic was 19.3 km (range: 0.8-217 km, SD: $25.3 \mathrm{~km}$ ).

Five questions on the questionnaire assessed patient knowledge about glaucoma. At the baseline visit, 16\% $(n=85)$ of participants correctly answered all five knowledge questions, and the remaining 84\% incorrectly answered one or more knowledge questions. At the follow-up visit, $39 \%(n=204)$ of participants correctly answered all five knowledge questions. A total of 51 participants correctly answered all knowledge questions at both baseline and follow-up, so change in knowledge was assessed in the remaining 467 participants. From baseline to follow-up, 
Table 3 Demographic characteristics of EQUALITY patients $(\mathrm{N}=5 \mid 8)$

\begin{tabular}{|c|c|}
\hline Demographic variables & $\begin{array}{l}\text { Mean } \\
\text { (SD) or } n \\
(\%) \\
\end{array}$ \\
\hline Age, mean years (SD) & $55.1(12.9)$ \\
\hline Sex, n (\%) female & $338(65.3)$ \\
\hline \multicolumn{2}{|l|}{ Race, n (\%) } \\
\hline African American & $333(64.3)$ \\
\hline White & $176(33.4)$ \\
\hline Other & $9(1.7)$ \\
\hline $\begin{array}{l}\text { Distance traveled to clinic from patient home address, } \\
\text { mean miles (SD) }\end{array}$ & $12.0(15.7)$ \\
\hline New patient to clinic, $\mathrm{n}(\%)$ yes & $173(33.4)$ \\
\hline Previous GAD, n (\%) yes & $142(27.6)$ \\
\hline Currently employed, $n(\%)$ yes & $277(53.6)$ \\
\hline Education level, n (\%) completed high school & $467(90.3)$ \\
\hline \multicolumn{2}{|l|}{ Comorbidities, $\mathrm{n}(\%)$} \\
\hline $0-1$ & $134(25.9)$ \\
\hline $2-3$ & $167(32.2)$ \\
\hline $4-5$ & $119(23.0)$ \\
\hline $6-12$ & $98(18.9)$ \\
\hline \multicolumn{2}{|l|}{ Time since last dilated eye exam } \\
\hline Within the past year, $\mathrm{n}(\%)$ & $170(32.8)$ \\
\hline More than a year ago but less than 2 years, $n(\%)$ & I54 (29.7) \\
\hline 2 or more years ago, $\mathrm{n}(\%)$ & $174(33.6)$ \\
\hline Never, n (\%) & $13(92.5)$ \\
\hline Don't know, n (\%) & $7(\mathrm{I} .4)$ \\
\hline Visual acuity, best eye mean BCVA logMAR (SD) & $0.039(0.10)$ \\
\hline Visual acuity, best eye mean walk-in VA logMAR (SD) & $0.34(0.38)$ \\
\hline Visual field, best eye mean MD (SD) & $4.61(5.94)$ \\
\hline
\end{tabular}

Abbreviations: EQUALITY, Eye Care Quality and Accessibility Improvement in the Community; SD, standard deviation; GAD, glaucoma-associated diagnosis; BCVA, best-corrected visual acuity; VA, visual acuity; logMAR, logarithm of the minimum angle of resolution; MD, mean deviation in decibels.

knowledge improved in $62 \%(n=288)$ of participants, while $38 \%(n=179)$ had no change in knowledge or a decline in knowledge.

Two questions were used to assess attitudes about eye care. At baseline, the majority $(n=363,70 \%)$ of participants had a positive attitude. At the follow-up visit, $80 \%(n=415)$ of participants had a positive attitude. Sixty-two percent $(n=318)$ of patients had a positive attitude on both attitude questions at both the baseline and follow-up visits; so change in attitude was assessed among the remaining 200 participants. From baseline to follow-up, $52 \%(n=104)$ improved to a more positive attitude, whereas $48 \%(n=96)$ had no change or had a less positive attitude at follow-up.

Table 4 describes the change in patient knowledge about glaucoma and attitudes about eye care for specific questions in each domain. All of the questions in both domains showed significant improvement in percent answered correctly (knowledge) or positively (attitude) from baseline to follow-up ( $P \leq 0.01$ for all questions).

Patients who correctly answered all knowledge questions at both baseline and follow-up were more likely to be younger, female, White, have better walk-in visual acuity, and have a history of GAD $(P<0.01)$ compared to those who did not correctly answer these questions. The patients who answered all knowledge questions correctly were also more likely to be employed and have more education, but these associations did not reach statistical significance $(P=0.17$ and $P=0.14$, respectively). Patients with a positive attitude at both baseline and follow-up were more likely to be White and have more education compared to everyone else (both $P<0.01$ ).

The multivariate model of factors associated with improvement in knowledge indicated that being unemployed (odds ratio $[\mathrm{OR}]=0.63,95 \%$ confidence interval $[\mathrm{CI}]=0.42-0.95, P=0.026)$ was significantly associated with a lower odds of improvement in glaucoma knowledge after adjusting for other participant-level factors, including age, sex, race, and prior glaucoma diagnosis (Table 5). There was some evidence of a moderate relationship between having less than a high school education

Table 4 Change in patient responses to questions on knowledge about glaucoma and attitudes about eye care

\begin{tabular}{|c|c|c|c|}
\hline Domain Questions & $\begin{array}{l}\text { Pre } \\
\text { (\% correct/ positive) }\end{array}$ & $\begin{array}{l}\text { Post } \\
\text { (\% correct/ positive) }\end{array}$ & $P$-value \\
\hline \multicolumn{4}{|l|}{ Knowledge domain questions ( $N=467)$} \\
\hline I. A person can have glaucoma and not know it. & 85.2 & 95.9 & $<0.001$ \\
\hline 2. Glaucoma can be controlled. & 70.2 & 79.4 & $<0.001$ \\
\hline 3. Vision lost from glaucoma can be restored. & 28.1 & 67.0 & $<0.001$ \\
\hline $\begin{array}{l}\text { 4. A complete glaucoma exam consists only of measuring eye } \\
\text { pressure. }\end{array}$ & 40.0 & 61.2 & $<0.001$ \\
\hline 5. People at risk for glaucoma should have a dilated eye exam. & 73.0 & 82.2 & $<0.001$ \\
\hline \multicolumn{4}{|l|}{ Attitude domain questions $(\mathrm{N}=200)$} \\
\hline 6. It is important to go to the eye doctor once every 2 years. & 68.0 & 81.5 & 0.001 \\
\hline $\begin{array}{l}\text { 7. There is no need to go to the eye doctor if you're not } \\
\text { having a problem with your eyes. }\end{array}$ & 48.0 & 67.0 & $<0.001$ \\
\hline
\end{tabular}

Abbreviations: Pre, baseline data; Post, follow-up data. 
Table 5 Multivariate analyses of factors associated with improvement in knowledge about glaucoma ( $\mathrm{N}=467)$

\begin{tabular}{|c|c|c|c|c|c|c|}
\hline \multirow[t]{2}{*}{ Variable } & \multicolumn{3}{|c|}{ Adjusted $^{\mathrm{a}}$} & \multicolumn{3}{|c|}{ Adjusted $^{\mathrm{b}}$} \\
\hline & OR & $95 \% \mathrm{Cl}$ & $P$-value & OR & $95 \% \mathrm{Cl}$ & $P$-value \\
\hline Age, years & 1.00 & $0.99-1.02$ & 0.697 & 1.02 & $1.0-1.05$ & $0.08 I$ \\
\hline \multicolumn{7}{|l|}{ Sex } \\
\hline Female & 1.10 & $0.74-1.64$ & 0.628 & 1.16 & $0.63-2.14$ & 0.632 \\
\hline Male & Ref & Ref & & Ref & Ref & \\
\hline \multicolumn{7}{|l|}{ Race } \\
\hline African American & 0.91 & $0.59-1.40$ & 0.671 & 1.17 & $0.60-1.30$ & 0.647 \\
\hline White & Ref & Ref & & Ref & Ref & \\
\hline \multicolumn{7}{|l|}{ Previous GAD } \\
\hline Yes & 1.00 & $0.65-1.54$ & $>0.999$ & 1.09 & $0.59-2.02$ & 0.777 \\
\hline No & Ref & Ref & & Ref & Ref & \\
\hline \multicolumn{7}{|l|}{ Currently employed } \\
\hline Yes & Ref & Ref & & Ref & Ref & \\
\hline No & 0.63 & $0.42-0.95$ & 0.026 & 0.61 & $0.32-1.16$ & 0.133 \\
\hline \multicolumn{7}{|l|}{ Education level } \\
\hline$<\mathrm{HS}$ & 0.55 & $0.29-1.02$ & 0.058 & 0.76 & $0.33-1.75$ & 0.520 \\
\hline$\geq \mathrm{HS}$ & Ref & Ref & & Ref & Ref & \\
\hline Visual acuity, logMAR & - & - & - & 0.55 & $0.20-1.48$ & 0.236 \\
\hline Mean deviation, $\mathrm{dB}$ & - & - & - & 0.98 & $0.93-1.03$ & 0.417 \\
\hline \multicolumn{7}{|c|}{ Number of comorbidities } \\
\hline $0-1$ & - & - & - & Ref & Ref & \\
\hline $2-3$ & - & - & - & 1.24 & $0.49-3.14$ & 0.643 \\
\hline $4-5$ & - & - & - & 0.93 & $0.34-2.55$ & 0.892 \\
\hline $6-12$ & - & - & - & 1.0 & $0.33-3.09$ & 0.994 \\
\hline
\end{tabular}

Notes: ${ }^{a}$ Adjusted includes the variables of age, sex, race, previous GAD, employment status, and education level. ${ }^{b}$ Adjusted includes the variables from Adjusted ${ }^{\mathrm{a}}$ as well as visual acuity, mean deviation, and number of comorbidities.

Abbreviations: OR, odds ratio; $\mathrm{Cl}$, confidence interval; GAD, glaucoma-associated diagnosis; HS, high school; dB, decibel; Ref, Reference; logMAR, logarithm of the minimum angle of resolution.

$(\mathrm{OR}=0.55,95 \% \mathrm{CI}=0.29-1.02, P=0.058)$ and a lower odds of improvement in glaucoma knowledge (Table 5). When the model was expanded to include visual acuity, visual field mean deviation, and number of medical comorbidities, employment status and educational level were no longer significantly associated with improvement in patient knowledge (Table 5). African American race (OR $=0.47$, $95 \%$ CI $=0.23-0.94, P=0.035$ ) was associated with less improvement in attitude compared to those of White race in the initial analysis (Table 6) but was no longer associated when the model was expanded (Table 6). A positive attitude at baseline was not associated with an improvement in knowledge about glaucoma.

Eye care utilization at baseline showed that $63 \%(n=324)$ of patients reported having had a dilated eye exam within the past two years. Of the remaining patients, $33.6 \%(n=174)$ had a dilated eye exam more than two years ago, $2.5 \%$ $(n=13)$ had never had a dilated eye exam, and $1.4 \%(n=7)$ didn't know if they had ever had an eye exam. After the eye health education and CEE, 507 of 517 ( $n=1$ missing, 98\%) patients reported that they were likely to have a CEE within the next 2 years, which is higher than those who had previously received a CEE. In addition, $300(58 \%)$ patients stated they were "more likely to go to the eye doctor if the doctor's office is near a place I shop". While only 57 (11\%) patients used the Walmart Pharmacy on the day of their exam, 294 (57\%) patients did some type of shopping in Walmart on the day of their exam.

Overall patient satisfaction with the experience in the EQUALITY program as measured on the follow-up questionnaire was high. Of the 518 patients, $514(99 \%)$ reported being satisfied with their CEE, whereas $516(99.6 \%)$ patients stated that they were likely "to recommend this eye clinic to a friend or family member". A total of 509 (98\%) patients stated that the clinic location where they had their exam was convenient for them.

\section{Discussion}

This study examined an evidence-based eye health education program provided within a retail-based telemedicine model. Our results suggest that after receiving an eye health education program about glaucoma, at-risk patients in the EQUALITY program improved their knowledge about glaucoma. These findings are consistent with other glaucoma education program evaluations, ${ }^{27,28}$ however, the other studies were based in nonclinical community settings, 
Table 6 Multivariate analyses of factors associated with improvement in attitude about eye care $(\mathrm{N}=200)$

\begin{tabular}{|c|c|c|c|c|c|c|}
\hline \multirow[t]{2}{*}{ Variable } & \multicolumn{3}{|c|}{ Adjusted $^{\mathrm{a}}$} & \multicolumn{3}{|c|}{ Adjusted $^{b}$} \\
\hline & OR & $95 \% \mathrm{Cl}$ & $P$-value & OR & $95 \% \mathrm{Cl}$ & $P$-value \\
\hline Age, years & 0.99 & $0.97-1.01$ & 0.332 & 1.01 & $0.97-1.06$ & 0.620 \\
\hline \multicolumn{7}{|l|}{ Sex } \\
\hline Female & 0.89 & $0.49-1.63$ & 0.711 & 0.90 & $0.33-2.43$ & 0.828 \\
\hline Male & Ref & Ref & & Ref & Ref & \\
\hline \multicolumn{7}{|l|}{ Race } \\
\hline African American & 0.47 & $0.23-0.94$ & 0.035 & 0.33 & $0.09-1.15$ & 0.083 \\
\hline White & Ref & Ref & & Ref & Ref & \\
\hline \multicolumn{7}{|l|}{ Previous GAD } \\
\hline Yes & 1.64 & $0.86-3.14$ & 0.135 & 2.13 & $0.73-6.19$ & 0.167 \\
\hline No & Ref & Ref & & Ref & Ref & \\
\hline \multicolumn{7}{|l|}{ Currently employed } \\
\hline Yes & Ref & Ref & & Ref & Ref & \\
\hline No & 1.12 & $0.59-2.13$ & 0.722 & 0.78 & $0.23-2.62$ & 0.688 \\
\hline \multicolumn{7}{|l|}{ Education level } \\
\hline$<\mathrm{HS}$ & 0.92 & $0.40-2.09$ & 0.837 & 0.81 & $0.24-2.76$ & 0.743 \\
\hline$\geq \mathrm{HS}$ & Ref & Ref & & Ref & Ref & \\
\hline Visual acuity, logMAR & - & - & - & 1.92 & $0.33-11.30$ & $0.47 \mid$ \\
\hline Mean deviation, $\mathrm{dB}$ & - & - & - & 1.04 & $0.94-1.15$ & 0.450 \\
\hline \multicolumn{7}{|c|}{ Number of comorbidities } \\
\hline $0-1$ & - & - & - & Ref & Ref & \\
\hline $2-3$ & - & - & - & 3.07 & $0.68-13.84$ & 0.145 \\
\hline $4-5$ & - & - & - & 0.36 & $0.07-1.86$ & 0.221 \\
\hline $6-12$ & - & - & - & 0.88 & $0.14-5.62$ & 0.892 \\
\hline
\end{tabular}

Notes: ${ }^{a}$ Adjusted includes the variables of age, sex, race, previous GAD, employment status, and education level. ${ }^{\mathrm{b}}$ Adjusted includes the variables from Adjusted as well as visual acuity, mean deviation, and number of comorbidities.

Abbreviations: OR, odds ratio; $\mathrm{Cl}$, confidence interval; GAD, glaucoma-associated diagnosis; HS, high school; dB, decibel; Ref, Reference; logMAR, logarithm of the minimum angle of resolution.

not within retail-based eye clinics. Significant improvement in patient knowledge within these accessible clinics may have been attained in the current study due to the use of multimedia, such as videos, pamphlets, and posters, to impart the educational message, because multimedia approaches can address a variety of patient-learning styles as recommended in recent studies by Rosdahl et $\mathrm{al}^{44}$ and Muir et al. ${ }^{56}$ In addition, the eye health education program trained clinic staff on how to impart knowledge about glaucoma to patients. The interaction of clinic staff with patients during the CEE may have also helped improve knowledge about glaucoma. ${ }^{44}$

Overall, those who were unemployed or had a lower education level were less likely to improve their glaucoma knowledge. After further adjusting for visual function and number of medical conditions, the association with education diminished, suggesting that these factors may be related to both educational attainment and improvement in knowledge. These multivariate results are limited, because the group of 51 patients who answered all glaucoma knowledge questions correctly at both baseline and follow-up were excluded. This group can be considered already at the "ceiling" of their glaucoma knowledge as tested by our questions. It is possible that the questions used to assess glaucoma knowledge were too basic, resulting in the large "ceiling" group. However, if this were the case, the "ceiling" group could have been even larger, and an improvement in knowledge may not have been shown.

The differences between those who were and were not in the models also shed light on the associations with knowledge improvement. The "ceiling" group was more likely to be younger, female, White, have better walk-in visual acuity, and have a history of GAD, with a trend toward more education and being employed. For example, while a prior glaucoma diagnosis, which presumably exposes a patient to prior glaucoma education as part of usual care, was not found to be associated with an improvement in knowledge in the multivariate analyses, it was a significant variable associated with the "ceiling" group of patients. Thus, it is highly likely that patients already diagnosed with glaucoma have received prior education from their eye care provider on glaucoma in the course of their care, resulting in higher baseline knowledge and health literacy.

Several studies have shown that lower education levels of patients are related to lack of knowledge about glaucoma as well as lower compliance with glaucoma therapy. ${ }^{56-61}$ The 
current study is also consistent with studies investigating the link between health literacy, defined as "the degree to which individuals have the capacity to obtain, process, and understand basic health information and services needed to make appropriate healthcare decisions", ${ }^{62}$ and health outcomes. A systematic review of health literacy studies found that health literacy was associated with level of education, ethnicity, and age ${ }^{63}$ similar to our study, in which patients who answered all glaucoma knowledge questions correctly at both baseline and follow-up tended to be more educated, White, and younger. Higher education may improve an individual's ability to use health information in ways that improve and maintain health. ${ }^{64}$ In studies on diabetes, patients with low health literacy are less compliant with treatment and have poorer outcomes. ${ }^{65}$ Muir et $\mathrm{al}^{56}$ found that poor health literacy and a poor understanding of glaucoma were associated with less adherence to glaucoma medication. Juzych et $\mathrm{al}^{61}$ demonstrated that poor health literacy among urban glaucoma patients was associated with demographic and socioeconomic factors, such as African American race, a high school education or less, and a household income less than $\$ 20,000$; poor compliance with glaucoma medications and appointments; poor understanding of glaucoma as a disease; and a worsening visual field. ${ }^{61}$ A lower education level, lower socioeconomic status, and poor health literacy may all be interrelated in negatively affecting health outcomes, including vision.

The results suggest that EQUALITY participants had generally positive attitudes about eye care even before the eye health education program - a finding similar to other studies. ${ }^{27,28}$ At follow-up, $80 \%$ of patients recognized the importance of going to an eye doctor every 2 years and the need to receive eye care even in the absence of an eye problem. Before EQUALITY, 63\% of patients reported having a $\mathrm{CEE}$ within the past 2 years, which is similar to previous studies. ${ }^{23,28}$ However, the accuracy of patient selfreporting of health care utilization has been shown to be highly variable. ${ }^{66}$ After the EQUALITY program, the results showed that $98 \%$ of study participants reported their intent to pursue a CEE within the next 2 years. This high percentage of patients who expressed their intention to have a CEE could be due to several factors. First, the eye health education program may have succeeded at its goal of educating patients at risk for glaucoma about the importance of routine eye care in detecting glaucoma. Second, it is possible that the "high-tech" nature of the telemedicine program with ultimate subspecialist review of patient data appealed to patients and made them feel that they were receiving tertiary level care without having to travel to such a center. That high amount of intent to pursue eye care in the future may be a result of the high level, nearly $100 \%$, of patient satisfaction with the EQUALITY care experience and may represent patients' eagerness to have a similar eye exam within the next 2 years. The question remains as to how well a patient's intent to pursue eye care utilization correlates with the patient's actual future eye care utilization. Future prospective studies evaluating the effectiveness of EQUALITY with a comparison group may be more suited to answer this.

The high level of patient satisfaction with the EQUALITY telemedicine program in the current study is consistent with other telemedicine glaucoma studies, ${ }^{33,67}$ as well as with the literature regarding telemedicine used to diagnose diabetic retinopathy. ${ }^{68,69}$ Patients also found it convenient to have their exam at the EQUALITY location, which could make it more likely that they will pursue eye care utilization using this model in the future, as the community-based eye care clinic is in close proximity to a large general retailer where patients routinely shop for necessary goods. A majority of patients even expressed that such a convenient location of the eye doctor near a place of shopping may improve their likelihood of pursuing eye care. The combination of convenience through a community-based retail eye clinic and tertiary level care provided by telemedicine is a novel approach to improve eye care utilization.

Strengths and limitations of the current study should be considered in the interpretation of the results. A strength is that the eye health education was focused on patients at high-risk for glaucoma, was delivered in a community-based accessible retail clinic, and was designed specifically for this group based on prior work by Owsley et $\mathrm{al}^{42}$ with a similar population. Also, in an effort to address the issue of possible low health literacy levels among patients, the eye health education program was written at a fifth-grade reading level. A study by Mikhail et $\mathrm{al}^{70}$ recently reported that regardless of literacy level, all patients in their study better understood educational material written at a fifth-grade level with illustrations. Another study by Muir et $\mathrm{al}^{71}$ demonstrated that glaucoma medication adherence improved after watching an educational video designed at a lower literacy level. ${ }^{71}$ Although patient literacy level was not objectively tested as in other studies, ${ }^{56,61,71}$ the level of highest education attained was recorded.

A limitation of the study is that approximately $20 \%$ of EQUALITY participants were not selected for inclusion in this analysis because of missing values on the baseline or follow-up surveys. An analysis of the excluded group showed that it was younger but otherwise similar in terms of race and sex to the present study sample analyzed in this paper. Given that higher 
baseline knowledge was seen in younger patients, the inclusion of the excluded group could have further increased the size of the "ceiling" group. Our measures on patient satisfaction were self-reported to an interviewer over the telephone; so reporting bias may be present. However, a single trained interviewer who followed the standardized script administered the survey; so any bias would likely be similar across participants. Since EQUALITY was designed as a demonstration program to establish feasibility, other weaknesses, including limiting participants to English speakers and the use of only two clinic sites, were due to limitations in the scale of the study. Future evaluation of the program may include eye health education written in Spanish as well as expansion to a greater number of clinics. Patients may have shown significant improvement in knowledge gained due to a short follow-up period of only 2-4 weeks after the education program exposure. It is possible that administering the follow-up questionnaire after a longer period would show a less significant improvement in knowledge. In addition, patients who were given a diagnosis of POAG, glaucoma suspect, or ocular hypertension at the conclusion of the CEE may have received additional education about glaucoma from the optometrist as part of usual care. This additional education could not be quantified or controlled for and was not used in the model. The improvement in knowledge, attitudes, and intent to pursue eye care, as well as the high patient satisfaction with the program might have occurred as a result of the patients' interactions in the primary eye care clinic devoid of the telemedicine and eye health education programs. While EQUALITY was developed as a demonstration program, an important next step in establishing telemedicine as an effective model of glaucoma care delivery is performing a comparative effectiveness evaluation between EQUALITY and a usual standard-of-care group.

\section{Conclusion}

Telemedicine is a possible strategy to improve disease detection and management by increasing access to and adherence with routine eye care. Using current technology, the EQUALITY telemedicine program allowed for the remote application of high-level clinical evaluation to community-based primary eye care clinics and provided an evidence-based eye health education program that improved knowledge about glaucoma and attitudes toward eye care. Improving patient knowledge about glaucoma and attitudes toward eye care in at-risk groups is important, because it may lead to increased eye care utilization and improved detection of early disease, thus lowering the risk of blindness.

\section{Acknowledgments}

This program was funded through a cooperative agreement with the Centers for Disease Control and Prevention (\#1U58DP004061) and a National Eye Institute grant (1K23EY025724-01A1), with supplemental support from the EyeSight Foundation of Alabama and Research to Prevent Blindness. The Centers for Disease Control and Prevention participated in the design, writing of the manuscript, and decision to submit the manuscript for publication. The EyeSight Foundation of Alabama and Research to Prevent Blindness did not participate in any aspect of the study. The findings and conclusions in this paper are those of the authors and do not necessarily reflect the official position of the Centers for Disease Control and Prevention.

\section{Disclosure}

The authors report no conflicts of interest in this work.

\section{References}

1. Quigley HA, West SK, Rodriquez J, Munoz B, Klein R, Snyder $\mathrm{R}$. The prevalence of glaucoma in a population-based study of Hispanic subjects: proyecto VER. Arch Ophthalmol. 2001;119: 1819-1826.

2. Tielsch JM, Sommer A, Katz J, Royall RM, Quigley HA, Javitt JC. Racial variations in the prevalence of primary open-angle glaucoma. JAMA. 1991;266:369-374.

3. Zhou M, Wang W, Huang W, Zhang X. Diabetes mellitus as a risk factor for open-angle glaucoma: a systematic review and meta-analysis. PLoS One. 2014;9:e102972.

4. Budenz DL, Barton K, Whiteside-de Vos J, et al. Prevalence of glaucoma in an urban West African population: the Tema Eye Survey. JAMA Ophthalmol. 2013;131(5):651-658.

5. Leske MC, Connell AM, Schachat AP, Hyman L. The Barbados Eye Study. Prevalence of open angle glaucoma. Arch Ophthalmol. 1994;112(6):821-829.

6. Leske MC, Connell AM, Wu SY, et al. Incidence of open-angle glaucoma: the Barbados Eye Studies. The Barbados Eye Studies Group. Arch Ophthalmol. 2001;119(1):89-95.

7. Munoz B, West SK, Rubin GS, et al. Causes of blindness and visual impairment in a population of older Americans: the Salisbury Eye Evaluation Study. Arch Ophthalmol. 2000;118(6):819-825.

8. Leske MC, Wu SY, Hennis A, Honkanen R, Nemesure B; BESs Study Group. Risk factors for incident open-angle glaucoma: the Barbados Eye Studies. Ophthalmology. 2008;115(1):85-93.

9. Agbeja-Baiyeroju AM, Bekibele CO, Bamgboye EA, Omokhodion F, Oluleye TS. The Ibadan glaucoma study. Afr J Med Med Sci. 2003;32(4): 371-376.

10. Kaimbo DK, Buntinx F, Missotten L. Risk factors for open-angle glaucoma: a case-control study. J Clin Epidemiol. 2001;54(2): 166-171.

11. Friedman DS, Wolfs RC, O'Colmain BJ, et al. Prevalence of openangle glaucoma among adults in the United States. Arch Ophthalmol. 2004;122:532-538.

12. BrightFocus.org [homepage on the Internet]. Glaucoma. Clarksburg, MD: Bright Focus Foundation. Available from: http://www.brightfocus.org/ glaucoma. Accessed August 17, 2015.

13. Javitt JC, Bean AM, Nicolson GA, Babish JD, Warren JL, Krakauer H. Undertreatment of glaucoma among black Americans. N Engl J Med. 1991;325:1418-1422. 
14. Wilson R, Richardson TM, Hertzmark E, Grant WM. Race as a risk factor for progressive glaucomatous damage. Ann Ophthalmol. 1985; 17:653-659.

15. Sommer A, Tielsch JM, Katz J, et al. Racial differences in the causespecific prevalence of blindness in east Baltimore. $N$ Engl J Med. 1991;325(20):1412-1417.

16. Grant WM, Burke JF Jr. Why do some people go blind from glaucoma? Ophthalmology. 1982;89:991-998.

17. Coulehan JL, Helzlsouer KJ, Rogers KD, Brown SI. Racial differences in intraocular tension and glaucoma surgery. Am J Epidemiol. 1980;111:759-768.

18. Martin MJ, Sommer A, Gold EB, Diamond EL. Race and primary open-angle glaucoma. Am J Ophthalmol. 1985;99:383-387.

19. David R, Livingston D, Luntz MH. Ocular hypertension: a comparative follow-up of black and white patients. $\mathrm{Br} J$ Ophthalmol. 1978;62:676-678.

20. Wilensky JT, Gandhi N, Pan T. Racial influences in open-angle glaucoma. Ann Ophthalmol. 1978;10:1398-1402.

21. MacLennan PA, McGwin GJ, Heckemeyer C, et al. Eye care utilization among a high-risk diabetic population seen in a public hospital's clinics. JAMA Ophthalmol. 2014;132:162-167.

22. Morales LS, Varma R, Paz SH, et al. Self-report use of eye care among Latinos: the Los Angeles Latino Eye Study. Ophthalmology. 2010;117:207-215.

23. Orr P, Barron Y, Schein OD, Rubin GS, West SK. Eye care utilization by older Americans: the SEE Project. Salisbury Eye Evaluation. Ophthalmology. 1999;106(5):904-909.

24. Bazargan M, Baker RS, Bazargan S. Correlates of recency of eye examination among elderly African-Americans. Ophthalmic Epidemiol. 1998;5(2):91-100.

25. Owsley C, McGwin G, Scilley K, Girkin CA, Phillips JM, Searcey K. Perceived barriers to care and attitudes about vision and eye care: focus groups with older African Americans and eye care providers. Invest Ophthalmol Vis Sci. 2006;47(7):2797-2802.

26. Basch CE, Walker EA, Howard CJ, Shamoon H, Zybert P. The effect of health education on the rate of ophthalmic examinations among African Americans with diabetes mellitus. Am J Public Health. 1999;89(12):1878-1882.

27. Owsley C, McGwin G, Stalvey BT, Weston J, Searcey K, Girkin CA. Educating older African-Americans about the preventive importance of routine comprehensive eye care. J Natl Med Assoc. 2008;100: 1089-1095.

28. Owsley C, McGwin G, Weston J, Stalvey B, Searcey K, Girkin CA. Preliminary evaluation of the InCharge program among African Americans in rural Alabama. J Health Dispar Res Pract. 2012;3(3): 115-126.

29. Ellish NJ, Royak-Schaler R, Passmore SR, Higginbotham EJ. Knowledge, attitudes, and beliefs about dilated eye examinations among African-Americans. Invest Ophthalmol Vis Sci. 2007;48(5): 1989-1994.

30. Li HK, Tang RA, Oschner K, Koplos C, Grady J, Crump WJ. Telemedicine screening of glaucoma. Telemed J. 1999;5(3):283-290.

31. Tuulonen A, Ohinmaa T, Alanko HI, Hyytinen P, Juutinen A, Toppinen E. The application of teleophthalmology in examining patients with glaucoma: a pilot study. J Glaucoma. 1999;8(6):367-373.

32. de Mul M, de Bont AA, Reus NJ, Lemij HG, Berg M. Improving the quality of eye care with tele-ophthalmology: shared-care glaucoma screening. J Telemed Telecare. 2004;10(6):331-336.

33. Blazquez F, Sebastian MA, Anton A. Detection of glaucoma using SisGlaTel: acceptability and satisfaction among participants, and problems detected. Arch Soc Esp Oftalmol. 2008;83(9):533-538. Spanish.

34. Kassam F, Amin S, Sogbesan E, Damji KF. The use of teleglaucoma at the University of Alberta. J Telemed Telecare. 2012;18(7):367-373.

35. Kassam F, Sogbesan E, Boucher S, et al. Collaborative care and teleglaucoma: a novel approach to delivering glaucoma services in Northern Alberta, Canada. Clin Exp Optom. 2013;96(6):577-580.
36. Kassam F, Yogesan K, Sogbesan E, Pasquale LR, Damji KF. Teleglaucoma: improving access and efficiency for glaucoma care. Middle East Afr J Ophthalmol. 2013;20(2):142-149.

37. Kiage D, Kherani IN, Gichuhi S, Damji KF, Nyenze M. The Muranga Teleophthalmology Study: comparison of virtual (teleglaucoma) with in-person clinical assessment to diagnose glaucoma. Middle East Afr J Ophthalmol. 2013;20(2):150-157.

38. Labiris G, Fanariotis M, Christoulakis C, et al. Tele-ophthalmology and conventional ophthalmology using a mobile medical unit in remote Greece. J Telemed Telecare. 2003;9(5):296-299.

39. Verma S, Arora S, Kassam F, Edwards MC, Damji KF. Northern Alberta remote teleglaucoma program: clinical outcomes and patient disposition. Can J Ophthalmol. 2014;49(2):135-140.

40. Strouthidis NG, Chandrasekharan G, Diamond JP, Murdoch IE Teleglaucoma: ready to go? Br J Ophthalmol. 2014;98:1605-1611.

41. Dreer LE, Owsley C, Campbell L, Gao L, Wood A, Girkin CA. Feasibility, patient acceptability, and preliminary efficacy of a culturally informed, health promotion program to improve glaucoma medication adherence among African Americans: "Glaucoma Management Optimism for African Americans Living with Glaucoma” (GOAL). Curr Eye Res. 2016;41(1):50-58.

42. Owsley C, McGwin G, Searcey K, et al. Effect of an eye health education program on older African Americans' eye care utilization and attitudes about eye care. J Natl Med Assoc. 2013;105(1):69-76.

43. Waterman H, Evans JR, Gray TA, Henson D, Harper R. Interventions for improving adherence to ocular hypotensive therapy. Cochrane Database Syst Rev. 2013;4:CD006132.

44. Rosdahl JA, Swamy L, Stinnett S, Muir KW. Patient education preferences in ophthalmic care. Patient Prefer Adherence. 2014;8: 565-574.

45. Owsley C, Rhodes L, McGwin G, et al. Eye Care Quality and Accessibility Improvement in the Community (EQUALITY) for Adults at risk for glaucoma: study rationale and design. Int J Equity Health. 2015;14:135.

46. Archibald J, Hansen J. The black belt: Alabama's third world. Special Report. The Birmingham News, 2002, May 12; Sect. A:1.

47. Prum BE, Jr, Rosenberg LF, Gedde SJ, et al. Primary open-angle glaucoma preferred practice pattern guidelines. Ophthalmology. 2016;123(1):41-111.

48. CDC.gov [homepage on the Internet]. Behavioral risk factor surveillance system. Atlanta, GA: Centers for Disease Control and Prevention. Available from: http://www.cdc.gov/brfss/. Accessed October 11, 2010.

49. Mangione CM, Lee PP, Gutierrez PR, et al. Development of the 25-item National Eye Institute Visual Function Questionnaire. Arch Ophthalmol. 2001;119(7):1050-1058.

50. Owsley C, McGwin G, Sloane M, Wells J, Stalvey BT, Gauthreaux S. Impact of cataract surgery on motor vehicle crash involvement by older adults. JAMA. 2002;288(7):841-849.

51. NEI.NIH.gov [homepage on the Internet]. National Eye Health Education Program. Bethesda, MD: National Eye Institute/National Institutes of Health. Available from: https://nei.nih.gov/glaucoma/ content/english/doyouknow. Accessed September 15, 2014.

52. PreventBlindness.org [homepage on the Internet]. The Glaucoma Educator Course. Prevent Blindness. Available from: http://www. preventblindness.org/content/resources-professionals. Accessed March 4, 2015.

53. PreventBlindness.org [homepage on the Internet]. Chicago, IL: Prevent Blindness. Available from: http://www.preventblindness.org/. Accessed March 30, 2015

54. Owsley C, McGwin G, Weston J, Stalvey BT, Searcey K, Girkin CA. Preliminary evaluation of the InCHARGE program among older African Americans in rural Alabama. $J$ Health Dispar Res Pract. 2010;3:115-126.

55. Beck RW, Moke PS, Turpin AH, et al. A computerized method of visual acuity testing: adaptation of the early treatment of diabetic retinopathy study testing protocol. Am J Ophthalmol. 2003;135(2): 194-205. 
56. Muir KW, Santiago-Turla C, Stinnett SS, et al. Health literacy and adherence to glaucoma therapy. Am J Ophthalmol. 2006;142(2): 223-226.

57. Gasch AT, Wang P, Pasquale LR. Determinants of glaucoma awareness in a general eye clinic. Ophthalmology. 2000;107(2):303-308.

58. Kim S, Stewart JF, Emond MJ, Reynolds AC, Leen MM, Mills RP. The effect of a brief education program on glaucoma patients. J Glaucoma. 1997;6(3):146-151.

59. Lau JT, Lee V, Fan D, Lau M, Michon J. Knowledge about cataract, glaucoma, and age related macular degeneration in the Hong Kong Chinese population. Br J Ophthalmol. 2002;86(10):1080-1084.

60. Hoevenaars JG, Schouten JS, van den Borne B, Beckers HJ, Webers CA. Socioeconomic differences in glaucoma patients' knowledge, need for information and expectations of treatments. Acta Ophthalmol Scand. 2006;84(1):84-91.

61. Juzych MS, Randhawa S, Shukairy A, Kaushal P, Gupta A, Shalauta N. Functional health literacy in patients with glaucoma in urban settings. Arch Ophthalmol. 2008;126(5):718-724.

62. HRSA.org [homepage on the Internet]. About health literacy. Rockville, MD: Health Resources and Services Administration. Available from: http://www.hrsa.gov/publichealth/healthliteracy/. Accessed August 17, 2015.

63. Paasche-Orlow MK, Parker RM, Gazmararian JA, Nielsen-Bohlman LT, Rudd RR. The prevalence of limited health literacy. J Gen Intern Med. 2005;20(2):175-184.
64. Grossman M. The Demand for Health: A Theoretical and Empirical Investigation. New York, NY: Columbia University Press; 1972.

65. Schillinger D, Grumbach K, Piette J, et al. Association of health literacy with diabetes outcomes. JAMA. 2002;288(4):475-482.

66. Bhandari A, Wagner T. Self-reported utilization of health care services: improving measurement and accuracy. Med Care Res Rev. 2006; 63(2):217-235.

67. Court JH, Austin MW. Virtual glaucoma clinics: patient acceptance and quality of patient education compared to standard clinics. Clin Ophthalmol. 2015;9:745-749.

68. Cavallerano AA, Conlin PR. Teleretinal imaging to screen for diabetic retinopathy in the Veterans Health Administration. J Diabetes Sci Technol. 2008;2(1):33-39.

69. Surendran TS, Raman R. Teleophthalmology in diabetic retinopathy. J Diabetes Sci Technol. 2014;8(2):262-266.

70. Mikhail D, Visscher KL, Chen N, Wang J, Emara BY, Hutnik CM. Patient-appropriate health literacy educational materials in ophthalmology. Can J Ophthalmol. 2015;50(1):19-25.

71. Muir KW, Ventura A, Stinnett SS, Enfiedjian A, Allingham RR, Lee PP. The influence of health literacy level on an educational intervention to improve glaucoma medication adherence. Patient Educ Couns. 2012;87(2):160-164.
Patient Related Outcome Measures

\section{Publish your work in this journal}

Patient Related Outcome Measures is an international, peer-reviewed, open access journal focusing on treatment outcomes specifically relevant to patients. All aspects of patient care are addressed within the journal and practitioners from all disciplines are invited to submit their work as well as healthcare researchers and patient support groups.

\section{Dovepress}

The manuscript management system is completely online and includes a very quick and fair peer-review system. Visit http://www.dovepress. com/testimonials.php to read real quotes from published authors. 